\title{
Assessment of Optical Quality at Different Contrast Levels in Pseudophakic Eyes
}

\author{
Chang Won Park, ${ }^{1}$ Hyojin Kim, ${ }^{2}$ and Choun-Ki Joo ${ }^{1}$ \\ ${ }^{1}$ Department of Ophthalmology and Institute for Visual Science, College of Medicine, The Catholic University of Korea, \\ Seoul 06591, Republic of Korea \\ ${ }^{2}$ Department of Visual Optics, Division of Health Science and Graduate School of Health and Welfare, Baekseok University, \\ Cheonan 31065, Republic of Korea \\ Correspondence should be addressed to Choun-Ki Joo; ckjoo@catholic.ac.kr
}

Received 26 August 2015; Revised 8 January 2016; Accepted 11 January 2016

Academic Editor: Tamer A. Macky

Copyright (C) 2016 Chang Won Park et al. This is an open access article distributed under the Creative Commons Attribution License, which permits unrestricted use, distribution, and reproduction in any medium, provided the original work is properly cited.

\begin{abstract}
Purpose. To assess visual function using Optical Quality Analysis System (OQAS) at varying levels of contrast in pseudophakic eyes. Methods. The study included patients admitted to Seoul St. Mary's Hospital between January and February 2012: 143 pseudophakic eyes with one of five intraocular lens types, examined 2-6 months after cataract surgery, and 93 normal eyes (enhanced visual acuity (VA) $<0.1 \log$ MAR) in age-matched controls. Subjects were examined at three contrast levels using the OQAS. Results. At $100 \%, 20 \%$, and $9 \%$ contrast, simulated mean VA was $0.16 \pm 0.18 \log \mathrm{MAR}, 0.30 \pm 0.18 \log \mathrm{MAR}$, and $0.52 \pm 0.17 \log \mathrm{MAR}$, in normal eyes, and $0.16 \pm 0.12 \log$ MAR, $0.33 \pm 0.20 \log M A R$, and $0.56 \pm 0.21 \log$ MAR, respectively, in pseudophakic eyes. Simulated VA decreased significantly when contrast was reduced, regardless of ocular status, age group, and lens type $(p<0.05)$. There were no significant differences between normal and pseudophakic eyes among subjects aged 50-69 $(p>0.05)$. Among subjects aged 70-79, pseudophakic eyes showed improved simulated VA $(p=0.000)$ and objective scattering index values $(p=0.008)$. Conclusions. Patients with intraocular lenses have similar or superior visual function when compared to those with normal eyes at 2-6 months after cataract surgery, even under low-contrast conditions.
\end{abstract}

\section{Introduction}

A cataract increases lens opacity and reduces visual acuity (VA), thus impairing the patient's quality of life [1]. The condition may even lead to blindness [2-4]. Surgical treatment is therefore necessary. Various techniques for cataract surgery have been developed since $\mathrm{H}$. Ridley introduced intraocular lenses (IOLs) composed of polymethylmethacrylate in 1949 [5]. The stability of IOLs allows cataract surgery to be commonly performed worldwide, and technological advancements such as multifocal and toric IOLs have increased the procedure's popularity $[6,7]$. To improve quality of life, cataract surgery is also performed for correcting refractive error [8-10].

In previous studies, postoperative VA, contrast sensitivity, and optical aberrations were measured as objective indices of surgical success [11-16]. After cataract surgery, improvement in VA is typically tested with a high-contrast (100\%) chart under photopic and mesopic conditions [17]. However, the level of contrast in the actual optical environment varies greatly [18]. For example, visual inspection of human facesof the utmost importance in daily life-involves a target of large size and low contrast. The change in VA after cataract surgery has not been studied under various levels of contrast. The aim of this study was to assess the visual performance of pseudophakic eyes after cataract surgery at different contrast levels by using the OQAS (Optical Quality Analysis System, Visiometrics, Terrassa, Spain).

\section{Materials and Methods}

This research was approved by the Institutional Review Board of the Catholic Medical Center at the Catholic University of Korea and conducted in accordance with ethical research 
guidelines. The present study adhered to the Declaration of Helsinki and was approved by the Institutional Review Board of the Catholic Medical Center at the Catholic University of Korea (approval number: KC12RISI0023). Patients completed an informed consent form approved by the institutional review board after the purpose of the study was explained to them. The study included patients admitted at Seoul St. Mary's Hospital between January and February 2012. No patients had a history of ocular surgery, ocular disease, or general disorders affecting vision (e.g., diabetic retinopathy) [19]. Vision of patients greater than $0.1 \log$ MAR was measured using the Snellen test and classified as age-matched (50s, 60s, and 70s) between normal and pseudophakic eyes. All patients underwent a comprehensive ophthalmologic examination, slit-lamp evaluation. The patients with pseudophakic eyes had undergone phacoemulsification and received one of five IOL types in the posterior chamber 2-6 months before the study. Patients were stratified into the following age groups: 50-59 years, 60-69 years, and 70-79 years.

Patients with failed IOL implantation into the lens capsule, severe posterior lens capsule opacification or history of laser capsulotomy due to opacification, or any other eye complication were excluded. Those with poor cooperation were also excluded. To prevent uncorrected refractive error from limiting contrast sensitivity or VA [20, 21], trial lenses were worn throughout testing. VA was measured using a Snellen chart at $6 \mathrm{~m}$. Altered contrast sensitivity was simulated with the OQAS by using the double-pass technique. With this approach, the retinal image, degree of haze inside the eye, and condition of visual function are analyzed in terms of objective scattering index (OSI), modulation transfer function (MTF) cut-off value, and Strehl ratio, respectively [22-25]. Simulated VA by OQAS was evaluated at contrast of $100 \%, 20 \%$, and $9 \%$.

Testing at each contrast level was performed for all five types of IOLs: HOYA PC-60AD (HOYA, Corp, Tokyo, Japan), EC-1PAL (Aaren Scientific, Ontario, Canada), Akreos MI-60 (Bausch \& Lomb, Rochester, NY, USA), NY-60 (HOYA, Corp, Tokyo, Japan), and XL Stabi ZO (Carl Zeiss Meditec, Jena, Germany).

One skilled tester (CWP) conducted all the measurements. The average values of three repeated measurements were analyzed. Analysis of variance (ANOVA) and independent-sample $t$-tests were performed using SPSS version 18.0 software (IBM Corporation, Armonk, NY). Values of $p<$ 0.05 were considered significant.

\section{Results and Discussion}

The subjects' characteristics are shown in Table 1. Mean visual acuities for the normal eyes were $0.16 \pm 0.18 \log \mathrm{MAR}, 0.30 \pm$ $0.18 \log$ MAR, and $0.52 \pm 0.17 \log$ MAR at $100 \%, 20 \%$, and $9 \%$ contrast, respectively (Table 2 ). In normal eyes from all age groups, simulated VA decreased significantly when contrast was reduced $(50-59, p=0.000 ; 60-69, p=0.000 ; 70-79, p=$ $0.020)$. However, simulated VA was highest among those aged 50-59 and lowest among those aged 70-79. Simulated VA at $100 \%$ and $9 \%$ contrast decreased with increasing age $(100 \%$, $p=0.045 ; 9 \%, p=0.010)$. No significant differences were noted among the age groups at $20 \%$ contrast $(p=0.070)$.
TABLE 1: Characteristics of normal $(N=93)$ and pseudophakic $(N=$ 143) eyes.

\begin{tabular}{ccc}
\hline Characteristic & Normal group & Pseudophakic group \\
\hline Eyes per age group $(n)$ & & \\
$50 \mathrm{~s}(\mathrm{M} / \mathrm{F})$ & $36(17,19)$ & $54(22,32)$ \\
$60 \mathrm{~s}(\mathrm{M} / \mathrm{F})$ & $45(25,20)$ & $77(30,47)$ \\
$70 \mathrm{~s}(\mathrm{M} / \mathrm{F})$ & $12(6,6)$ & $12(5,7)$ \\
Age (years) & $62.39 \pm 6.60$ & $63.21 \pm 6.74$ \\
Total gender & $48 / 45$ & $57 / 86$ \\
\hline
\end{tabular}

Values are presented as mean $\pm \mathrm{SD}$.

TABLE 2: Simulated visual acuity (mean VA $\log M A R \pm S D$ ) of normal eyes $(N=93)$ at different simulated contrast levels compared by age group.

\begin{tabular}{lcccc}
\hline Age group & \multicolumn{5}{c}{ Contrast } \\
& $100 \%$ & $20 \%$ & $9 \%$ & $p^{*}$ \\
\hline $50 \mathrm{~s}$ & $0.12 \pm 0.11$ & $0.24 \pm 0.15$ & $0.45 \pm 0.14$ & 0.000 \\
$60 \mathrm{~s}$ & $0.16 \pm 0.18$ & $0.31 \pm 0.19$ & $0.55 \pm 0.18$ & 0.000 \\
$70 \mathrm{~s}$ & $0.27 \pm 0.20$ & $0.47 \pm 0.20$ & $0.68 \pm 0.16$ & 0.020 \\
Total & $0.16 \pm 0.18$ & $0.30 \pm 0.18$ & $0.52 \pm 0.17$ & 0.000 \\
\hline$p^{* *}$ & 0.045 & 0.070 & 0.010 & \\
\hline
\end{tabular}

${ }^{*}$ ANOVA among contrast levels.

${ }^{* *}$ ANOVA among age groups.

TABLE 3: Simulated visual acuity (mean VA $\log M A R \pm S D$ ) of pseudophakic eyes $(N=143)$ at different simulated contrast levels, compared by age group.

\begin{tabular}{lcccc}
\hline Age group & \multicolumn{5}{c}{ Contrast } \\
& $100 \%$ & $20 \%$ & $9 \%$ & $p^{*}$ \\
\hline $50 \mathrm{~s}$ & $0.12 \pm 0.16$ & $0.29 \pm 0.24$ & $0.53 \pm 0.21$ & 0.000 \\
$60 \mathrm{~s}$ & $0.18 \pm 0.15$ & $0.35 \pm 0.23$ & $0.59 \pm 0.22$ & 0.000 \\
$70 \mathrm{~s}$ & $0.19 \pm 0.10$ & $0.37 \pm 0.14$ & $0.55 \pm 0.19$ & 0.000 \\
Total & $0.16 \pm 0.12$ & $0.33 \pm 0.20$ & $0.56 \pm 0.21$ & 0.000 \\
\hline$p^{* *}$ & 0.269 & 0.263 & 0.332 & \\
\hline
\end{tabular}

* ANOVA among contrast levels.

**ANOVA among age groups.

For pseudophakic eyes, mean visual acuities were $0.16 \pm$ $0.12 \log \mathrm{MAR}, 0.33 \pm 0.20 \log \mathrm{MAR}$, and $0.56 \pm 0.21 \log \mathrm{MAR}$ at $100 \%, 20 \%$, and $9 \%$ contrast, respectively (Table 3 ). As in the normal eyes, VA decreased significantly when contrast was reduced $(p=0.000)$. However, nova was similar in all age groups $(p>0.05)$.

Figure 1 shows simulated VA for the normal and pseudophakic eyes in each age group at all contrast levels. No significant difference in VA was noted among those aged 5069 . However, among those aged 70-79, the pseudophakic eyes exhibited significantly higher VA $(p=0.000)$.

Table 4 shows the simulated mean visual acuities of the pseudophakic eyes according to IOL type. Subjects implanted with EC-1PAL and NY-60 IOLs showed the lowest and the highest VA, respectively, although no significant differences were noted among IOLs at any contrast level. Regardless of 

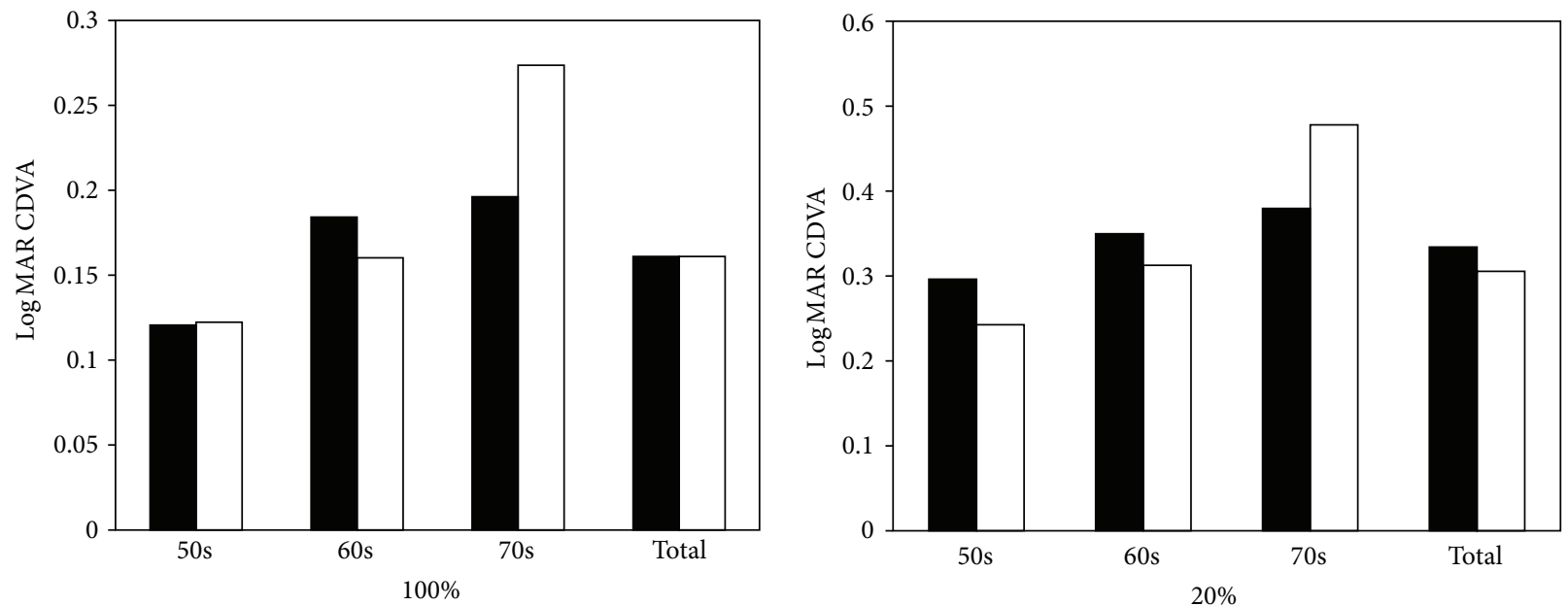

- Pseudophakic eye $\square$ Normal eye

- Pseudophakic eye

$\square$ Normal eye

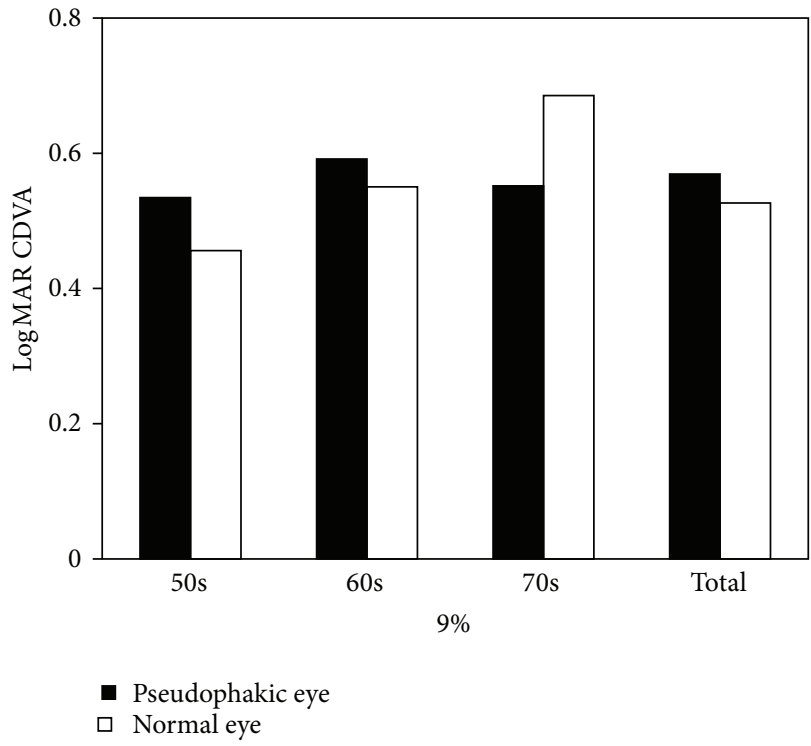

FIGURE 1: Simulated visual acuity (mean VA $\log M A R \pm S D$ ) of normal versus pseudophakic eyes at various simulated contrast levels, compared by age group.

TABLE 4: Simulated visual acuity (mean VA $\log M A R \pm S D)$ of pseudophakic eyes $(N=143)$ at different contrast levels, compared by intraocular lens type.

\begin{tabular}{lcccc}
\hline \multirow{2}{*}{ Intraocular lens $(n)$} & \multicolumn{4}{c}{ Contrast } \\
& $100 \%$ & $20 \%$ & $9 \%$ & $p^{*}$ \\
\hline HOYA PC-60AD (42) & $0.17 \pm 0.25$ & $0.33 \pm 0.26$ & $0.57 \pm 0.23$ & 0.000 \\
EC-1PAL (36) & $0.18 \pm 0.19$ & $0.34 \pm 0.18$ & $0.57 \pm 0.16$ & 0.000 \\
Akreos MI-60 (25) & $0.14 \pm 0.27$ & $0.34 \pm 0.25$ & $0.58 \pm 0.22$ & 0.000 \\
NY-60 (21) & $0.09 \pm 0.16$ & $0.27 \pm 0.18$ & $0.53 \pm 0.19$ & 0.000 \\
XL Stabi ZO (19) & $0.19 \pm 0.22$ & $0.33 \pm 0.20$ & $0.56 \pm 0.18$ & 0.000 \\
\hline$p^{* *}$ & 0.413 & 0.684 & 0.870 & \\
\hline
\end{tabular}

${ }^{*}$ ANOVA among contrast levels.

**ANOVA among lens types.

IOL type, VA decreased significantly when contrast was reduced $(p=0.000)$.
OSI value, MTF cut-off value, and Strehl ratio values are presented in Table 5. The mean values were $2.21 \pm 1.38,23.29 \pm$ 10.72 , and $0.18 \pm 0.47$, respectively, in the pseudophakic group and $1.99 \pm 1.41,23.41 \pm 9.72$, and $0.13 \pm 0.07$, respectively, in the normal group. The only significant finding was elevated OSI values in normal eyes from the 70-79 age group ( $p=$ 0.008 ). Figure 2 shows representative OQAS results obtained from a 69-year-old patient with normal eyes and a 72-yearold patient with pseudophakic eyes.

In addition to questionnaires, VA and contrast sensitivity assessments are used to evaluate ocular health after cataract surgery. Recent technological advancements have allowed for the measurement of higher-order aberrations including spherical aberration and coma aberration [26] as well as the optical analysis of light spread within the eye (point spread function) [27-29]. However, such tests are useful only in characterizing symptoms [30]. Anera et al. [31] and Artal et al. 
Objective refraction images

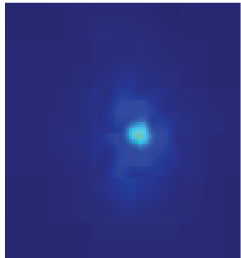

$-0.750$

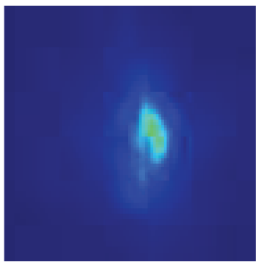

$-1.000$

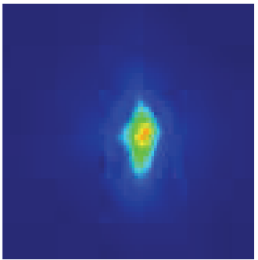

$-1.250$

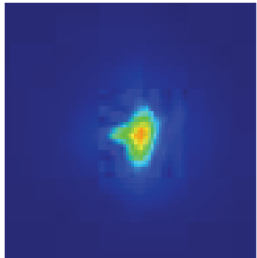

$-1.500$

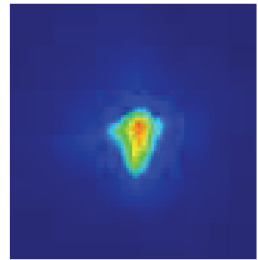

$-1.750$

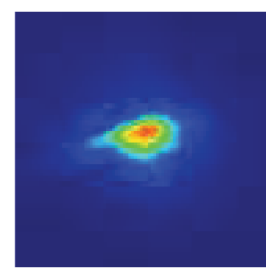

$-2.000$

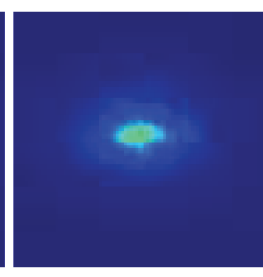

$-2.250$

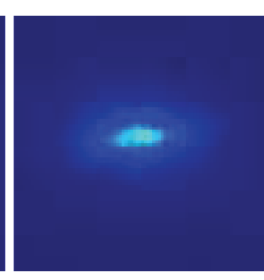

$-2.500$

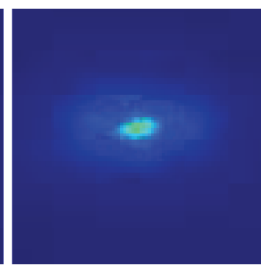

$-2.750$
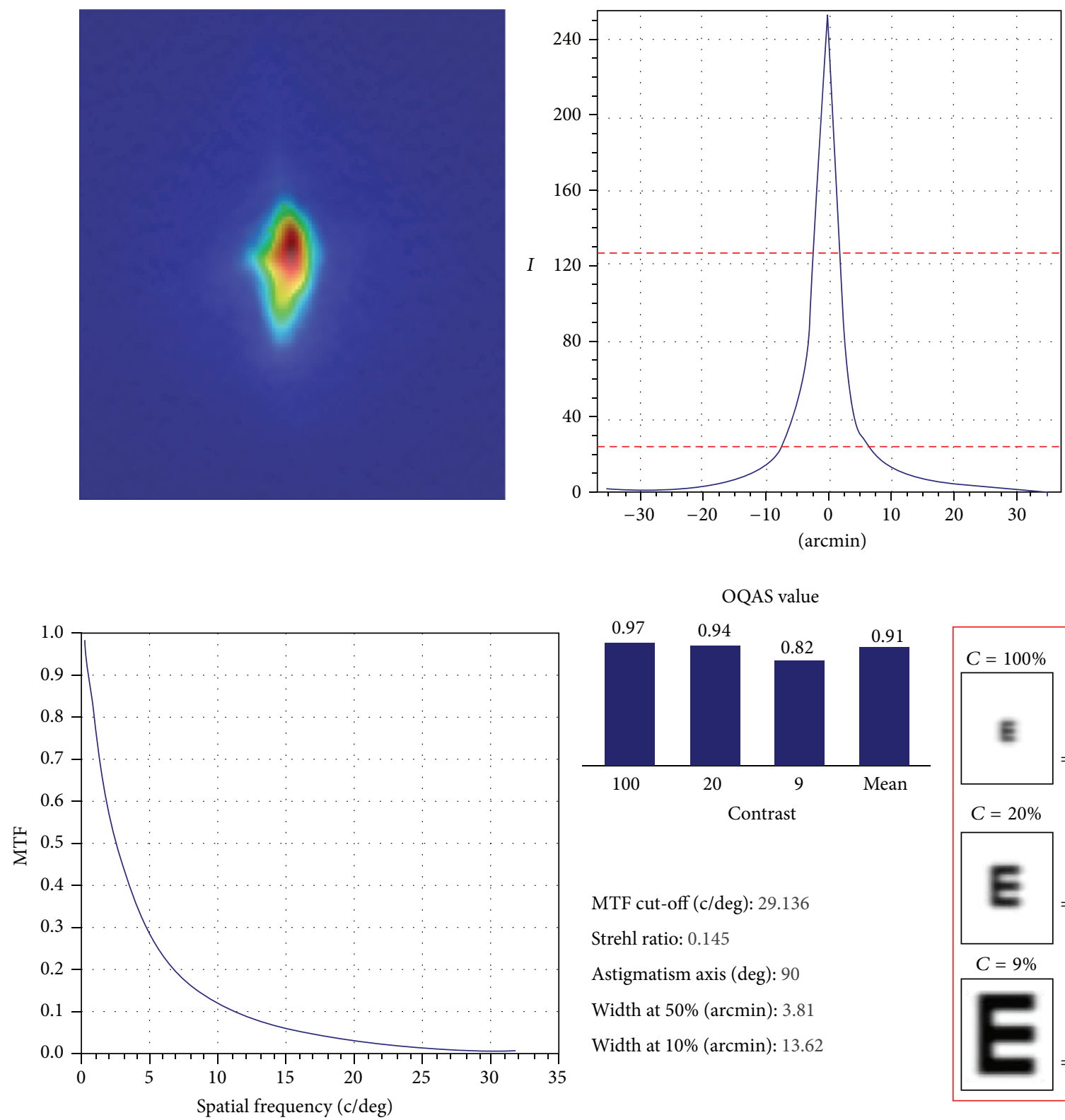

OQAS value
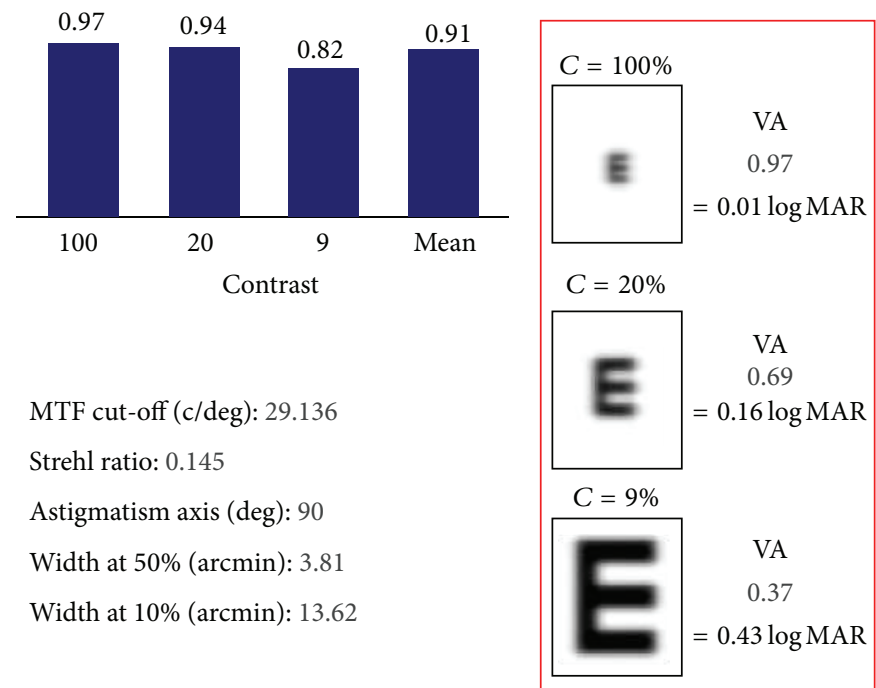

MTF cut-off (c/deg): 29.136

Strehl ratio: 0.145

Astigmatism axis (deg): 90

Width at $50 \%$ (arcmin): 3.81

Width at $10 \%$ (arcmin): 13.62

$=0.43 \log \mathrm{MAR}$ 
Objective refraction images

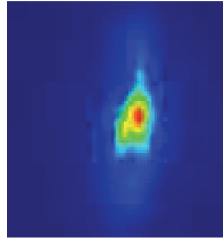

0.500

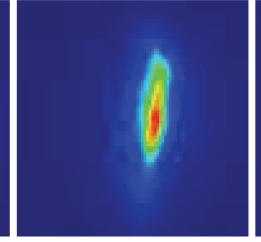

0.250

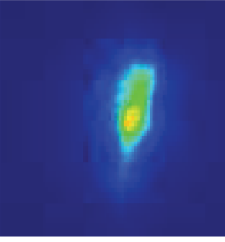

0.000

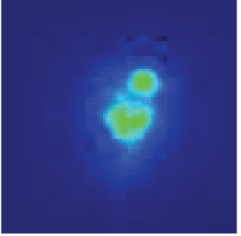

$-0.250$

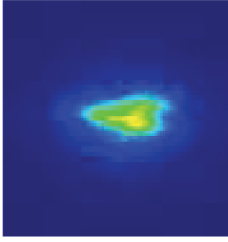

$-0.500$

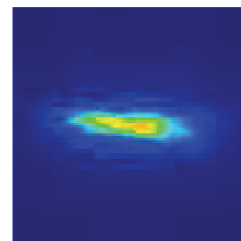

$-0.750$

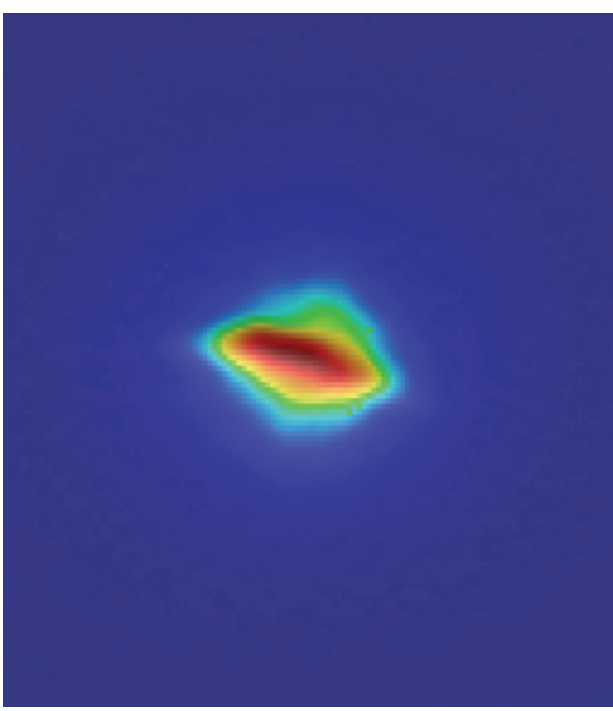

$-1.000$

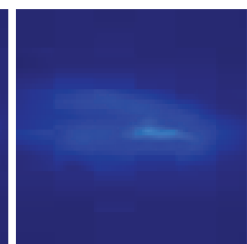

$-1.250$

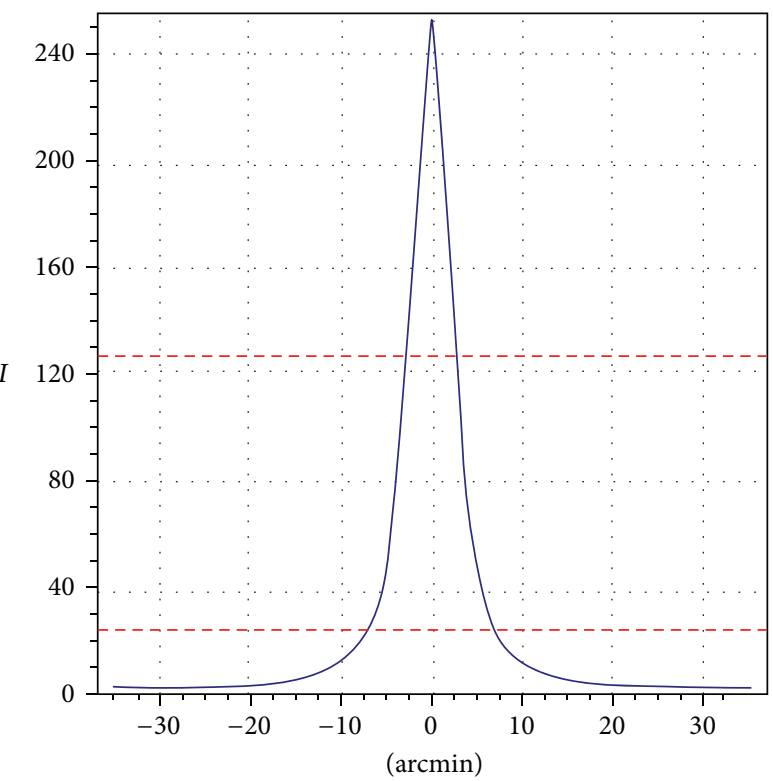

OQAS value

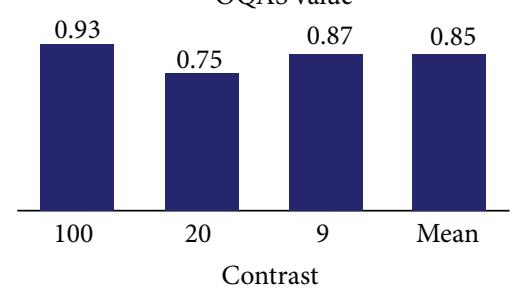

MTF cut-off (c/deg): 27.769

Strehl ratio: 0.161

Astigmatism axis (deg): 169

Width at $50 \%$ (arcmin): 5.41

Width at $10 \%(\operatorname{arcmin}): 13.53$

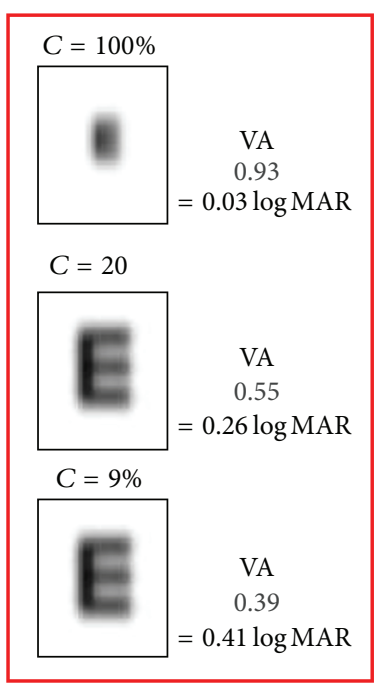

(b)

FIGURE 2: Representative OQAS results of (a) normal and (b) pseudophakic eyes. The red rectangles show Sim VA (simulated visual acuity) at different simulated contrast levels. 
TABLE 5: OQAS parameters (mean \pm SD) of normal $(N=93)$ and pseudophakic $(N=143)$ eyes, stratified by age group.

\begin{tabular}{lcccc}
\hline Parameter & $\begin{array}{c}\text { Age } \\
\text { group }\end{array}$ & Normal group & $\begin{array}{c}\text { Pseudophakic } \\
\text { group }\end{array}$ & $p^{*}$ \\
\hline \multirow{3}{*}{ OSI (OSI } & $50 \mathrm{~s}$ & $1.82 \pm 1.19$ & $2.05 \pm 1.28$ & 0.625 \\
value) & $60 \mathrm{~s}$ & $1.92 \pm 1.11$ & $2.32 \pm 1.52$ & 0.329 \\
& $70 \mathrm{~s}$ & $3.96 \pm 2.29$ & $2.15 \pm 1.31$ & 0.008 \\
& Total & $1.99 \pm 1.41$ & $2.21 \pm 1.38$ & 0.940 \\
\hline \multirow{3}{*}{ MTF cut-off } & $50 \mathrm{~s}$ & $22.29 \pm 7.88$ & $25.73 \pm 11.38$ & 0.273 \\
value (C/deg) & $60 \mathrm{~s}$ & $23.09 \pm 10.72$ & $22.36 \pm 10.93$ & 0.773 \\
& $70 \mathrm{~s}$ & $15.83 \pm 9.14$ & $22.04 \pm 9.48$ & 0.090 \\
& Total & $23.41 \pm 9.72$ & $23.29 \pm 10.72$ & 0.925 \\
\hline \multirow{3}{*}{ Strehl ratio } & $50 \mathrm{~s}$ & $0.13 \pm 0.07$ & $0.15 \pm 0.15$ & 0.356 \\
& $60 \mathrm{~s}$ & $0.12 \pm 0.05$ & $0.14 \pm 0.13$ & 0.452 \\
& $70 \mathrm{~s}$ & $0.10 \pm 0.03$ & $0.13 \pm 0.03$ & 0.442 \\
& Total & $0.13 \pm 0.07$ & $0.18 \pm 0.47$ & 0.498 \\
\hline
\end{tabular}

${ }^{*} t$-test.

OSI: objective scattering index; MTF: modulation transfer function.

[32] used the OQAS to measure the OSI, MTF cut-off value, and Strehl ratio after cataract and refractive surgeries and to assess visual function objectively. The OQAS can also be used to simulate contrast changes. In this study, we investigated vision at three contrast levels simulated using the OQAS and stratified subjects with normal and pseudophakic eyes by age.

Among patients in their 50s and 60s, normal eyes exhibited Sim VA superior or similar to that of pseudophakic eyes. However, among those in their 70s, pseudophakic eyes had significantly superior VA $(p=0.000)$. Cataract surgery may have restored visual function in these patients. Alternatively, the normal eyes in this age group may have been free of any lens opacity that could be detected by slit-lamp examination but may have had fine opacities in the lens and/or vitreous chamber that scattered light, thereby reducing VA. Another significant finding was the lower OSI value of the pseudophakic eyes in this group $(p=0.008)$, which is in line with the report by Saad et al. [33] that OSI values increase with age in normal eyes.

In both the normal and pseudophakic groups, VA was directly related to contrast level regardless of age. Furthermore, VA decreased as age increased; as reported by Mathai et al. [34] Sim VA was similar in normal and pseudophakic eyes of subjects aged 50-69 but superior in the pseudophakic eyes of subjects aged 70-79 years. Therefore, visual function must have returned to normal levels in all patients with IOLs at 2-6 months after cataract surgery.

The NY-60 and EC-1PAL IOLs were associated with the highest and lowest visual acuities, respectively, regardless of contrast level. Interestingly, use of the NY-60 IOL is reportedly associated with fewer capsular folds than use of a threepiece IOL [35]. NY-60 IOL users also report the absence of entoptic phenomena [36] 1 year after surgery. In an eye with an IOL, the presence of entoptic phenomena correlates directly with the OSI value [37]. This relationship may explain the superior VA of the NY-60 group, although this improvement in VA was associated with use of the AcrySof SN60WF and TECNIS ZCBO0 IOLs in previous reports [38]. In this study, reduced contrast was associated with decreased acuity across groups, but no significant difference in simulated VA among IOL types was noted at any contrast level ( $p=0.413$ ).

A possible limitation of our study is that the OQAS's HeNe diode laser may have introduced error to the OSI readings, for example, in patients with dry eye symptoms or cloudy vitreous, which scatters light. High scatter increases OSI values.

\section{Conclusion}

In summary, VA at 2-6 months after cataract surgery in pseudophakic eyes is similar to that of normal eyes and older patients with pseudophakic eyes have superior simulated VA to age-matched controls, contrary to previous reports that the level of contrast and age affect visual function. These findings suggest that IOLs ensure simulated VA similar to that of the normal eye even in very low-contrast conditions, as encountered when driving at night. Therefore, IOL implantation should have a beneficial impact on the patient's quality of life. The OQAS seems to be a useful instrument for the objective evaluation of visual quality under contrast after various surgeries such as cataract surgery, laser-assisted in situ keratomileusis (LASIK), laser-assisted subepithelial keratectomy (LASEK), and keratoconus surgery.

\section{Conflict of Interests}

The authors report no conflict of interests. The authors alone are responsible for the content and writing of the paper.

\section{Acknowledgment}

The authors appreciate dedication of the Department of Ophthalmology and Visual Science, Seoul St. Mary's Hospital, The Catholic University of Korea.

\section{References}

[1] M. K. Shields, R. J. Casson, J. Muecke et al., "Intermediate-term cataract surgery outcomes from rural provinces in Lao People's Democratic Republic," Ophthalmic Epidemiology, vol. 22, no. 4, pp. 260-265, 2015.

[2] M. B. Alhassan, F. Kyari, and H. O. Ejere, "Peribulbar versus retrobulbar anaesthesia for cataract surgery," Cochrane Database of Systematic Reviews, no. 7, Article ID CD004083, 2015.

[3] T. Li, L. Du, and L. Du, "Prevalence and causes of visual impairment and blindness in Shanxi Province, China," Ophthalmic Epidemiology, vol. 22, no. 4, pp. 239-245, 2015.

[4] S. Lewallen, E. Schmidt, E. Jolley et al., "Factors affecting cataract surgical coverage and outcomes: a retrospective crosssectional study of eye health systems in sub-Saharan Africa," BMC Ophthalmology, vol. 15, no. 1, article 67, 2015.

[5] D. J. Apple and J. Sims, "Harold Ridley and the invention of the intraocular lens," Survey of Ophthalmology, vol. 40, no. 4, pp. 279-292, 1996. 
[6] M. D. Leyland, L. Langan, F. Goolfee, N. Lee, and P. A. Bloom, "Prospective randomised double-masked trial of bilateral multifocal, bifocal or monofocal intraocular lenses," Eye, vol. 16, no. 4, pp. 481-490, 2002.

[7] H. S. Choi and H. B. Kim, "Clinical results of unilateral implantation of AMO Array ${ }^{\oplus}$ multifocal intraocular lens," Journal of the Korean Ophthalmological Society, vol. 42, no. 5, pp. 702-708, 2001.

[8] A. Iovieno, S. N. Yeung, A. Lichtinger, M. Alangh, A. R. Slomovic, and D. S. Rootman, "Cataract surgery with toric intraocular lens for correction of high corneal astigmatism," Canadian Journal of Ophthalmology, vol. 48, no. 4, pp. 246-250, 2013.

[9] T. Seiler, W. Reckmann, and R. K. Maloney, "Effective spherical aberration of the cornea as a quantitative descriptor in corneal topography," Journal of Cataract and Refractive Surgery, vol. 19, pp. 155-165, 1993.

[10] K. L. Waltz, K. Featherstone, L. Tsai, and D. Trentacost, "Clinical outcomes of TECNIS toric intraocular lens implantation after cataract removal in patients with corneal astigmatism," Ophthalmology, vol. 122, no. 1, pp. 39-47, 2015.

[11] D. Ortiz, J. L. Alió, G. Bernabéu, and V. Pongo, "Optical performance of monofocal and multifocal intraocular lenses in the human eye," Journal of Cataract and Refractive Surgery, vol. 34, no. 5, pp. 755-762, 2008.

[12] T. Iwase, N. Tanaka, and K. Sugiyama, "Postoperative refraction changes in phacoemulsification cataract surgery with implantation of different types of intraocular lens," European Journal of Ophthalmology, vol. 18, no. 3, pp. 371-376, 2008.

[13] M. Kugelberg, G. Wejde, H. Jayaram, and C. Zetterström, "Posterior capsule opacification after implantation of a hydrophilic or a hydrophobic acrylic intraocular lens: one-year follow-up," Journal of Cataract and Refractive Surgery, vol. 32, no. 10, pp. 1627-1631, 2006.

[14] A. E. Barañano, J. Wu, K. Mazhar, S. P. Azen, and R. Varma, "Visual acuity outcomes after cataract extraction in adult Latinos. The Los Angeles Latino Eye study," Ophthalmology, vol. 115, no. 5, pp. 815-821, 2008.

[15] J. Lau, J. J. Michon, W.-S. Chan, and L. B. Ellwein, "Visual acuity and quality of life outcomes in cataract surgery patients in Hong Kong," British Journal of Ophthalmology, vol. 86, no. 1, pp. 12-17, 2002.

[16] H. Kapoor, A. Chatterjee, R. Daniel, and A. Foster, "Evaluation of visual outcome of cataract surgery in an Indian eye camp," British Journal of Ophthalmology, vol. 83, no. 3, pp. 343-346, 1999.

[17] A. Denoyer, M.-L. Le Lez, S. Majzoub, and P.-J. Pisella, "Quality of vision after cataract surgery after Tecnis Z9000 intraocular lens implantation: effect of contrast sensitivity and wavefront aberration improvements on the quality of daily vision," Journal of Cataract and Refractive Surgery, vol. 33, no. 2, pp. 210-216, 2007.

[18] L. F. Jindra and V. Zemon, "Contrast sensitivity testing: a more complete assessment of vision," Journal of Cataract and Refractive Surgery, vol. 15, no. 2, pp. 141-148, 1989.

[19] S. A. Lim, J. H. Hwang, K.-Y. Hwang, and S.-H. Chung, "Objective assessment of nuclear cataract: comparison of double-pass and Scheimpflug systems," Journal of Cataract and Refractive Surgery, vol. 40, no. 5, pp. 716-721, 2014.

[20] F. T. Oen, T. H. Lim, and M. P. Chung, "Contrast sensitivity in a large adult population," Annals of the Academy of Medicine Singapore, vol. 23, no. 3, pp. 322-326, 1994.
[21] R. L. Woods, N. C. Strang, and D. A. Atchison, "Measuring contrast sensitivity with inappropriate optical correction," Ophthalmic and Physiological Optics, vol. 20, no. 6, pp. 442-451, 2000.

[22] F. Díaz-Doutón, A. Benito, J. Pujol, M. Arjona, J. L. Güell, and P. Artal, "Comparison of the retinal image quality with a Hartmann-Shack wavefront sensor and a double-pass instrument," Investigative Ophthalmology and Visual Science, vol. 47, no. 4, pp. 1710-1716, 2006.

[23] D. Ortiz, J. L. Alió, J. Ruiz-Colechá, and U. Oser, “Grading nuclear cataract opacity by densitometry and objective optical analysis," Journal of Cataract and Refractive Surgery, vol. 34, no. 8, pp. 1345-1352, 2008.

[24] M. Vilaseca, M. Arjona, J. Pujol, L. Issolio, and J. L. Güell, "Optical quality of foldable monofocal intraocular lenses before and after injection: comparative evaluation using a double-pass system," Journal of Cataract and Refractive Surgery, vol. 35, no. 8, pp. 1415-1423, 2009.

[25] K. W. Brydon, A. C. Tokarewicz, and B. D. Nichols, "Amo array multifocal lens versus monofocal correction in cataract surgery," Journal of Cataract and Refractive Surgery, vol. 26, no. 1, pp. 96-100, 2000.

[26] Y.-J. Li, J. A. Choi, H. Kim, S.-Y. Yu, and C.-K. Joo, "Changes in ocular wavefront aberrations and retinal image quality with objective accommodation," Journal of Cataract and Refractive Surgery, vol. 37, no. 5, pp. 835-841, 2011.

[27] C. M. Mangione, P. P. Lee, J. Pitts, P. Gutierrez, S. Berry, and R. D. Hays, "Psychometric properties of the National Eye Institute Visual Function Questionnaire (NEI-VFQ). NEI-VFQ Field Test Investigators," Archives of Ophthalmology, vol. 116, no. 11, pp. 1496-1504, 1998.

[28] C. M. Mangione, P. P. Lee, P. R. Gutierrez, K. Spritzer, S. Berry, and R. D. Hays, "Development of the 25 -item national eye institute visual function questionnaire," Archives of Ophthalmology, vol. 119, no. 7, pp. 1050-1058, 2001.

[29] A. Castillo-Gómez, D. Carmona-González, J. M. Martínezde-la-Casa, C. Palomino-Bautista, and J. García-Feijoo, "Evaluation of image quality after implantation of 2 diffractive multifocal intraocular lens models," Journal of Cataract and Refractive Surgery, vol. 35, no. 7, pp. 1244-1250, 2009.

[30] H. Kim and C.-K. Joo, "Visual quality after wavefront-guided LASIK for myopia," Journal of Korean Medical Science, vol. 20, no. 5, pp. 860-865, 2005.

[31] R. G. Anera, J. J. Castro, J. R. Jiménez, C. Villa, and A. Alarcón, "Optical quality and visual discrimination capacity after myopic LASIK with a standard and aspheric ablation profile," Journal of Refractive Surgery, vol. 27, no. 8, pp. 597-601, 2011.

[32] P. Artal, A. Benito, G. M. Pérez et al., "An objective scatter index based on double-pass retinal images of a point source to classify cataracts," PLoS ONE, vol. 6, no. 2, Article ID e16823, 2011.

[33] A. Saad, M. Saab, and D. Gatinel, "Repeatability of measurements with a double-pass system," Journal of Cataract and Refractive Surgery, vol. 36, no. 1, pp. 28-33, 2010.

[34] A. Mathai, R. Thomas, A. Braganza, S. Maharajan, T. George, and J. Muliyil, "Vistech contrast sensitivity testing in primary open angle glaucoma," Indian Journal of Ophthalmology, vol. 45, no. 2, pp. 99-103, 1997.

[35] A. Prinz, P. V. V. Marlovits, D. Sonderhof, P. Irsigler, O. Findl, and B. Weingessel, "Comparison of posterior capsule opacification between a 1-piece and a 3-piece microincision intraocular lens," British Journal of Ophthalmology, vol. 97, no. 1, pp. 18-22, 2013. 
[36] C. Leydolt, S. Schriefl, E. Stifter, A. Haszcz, and R. Menapace, "Posterior capsule opacification with the iMics1 NY-60 and AcrySof SN60WF 1-piece hydrophobic acrylic intraocular lenses: 3-year results of a randomized trial," American Journal of Ophthalmology, vol. 156, no. 2, pp. 375.e2-381.e2, 2013.

[37] E. Alcon, A. Benito, G. M. Perez et al., "Quantifying intraocular scattering in cataract patients," Investigative Ophthalmology and Visual Science, vol. 48, no. 13, E-Abstract 3822, 2007.

[38] K. H. Lee, M. H. Yoon, K. Y. Seo, E. K. Kim, and T. I. Kim, "Comparisons of clinical results after implantation of three aspheric intraocular lenses," Journal of the Korean Ophthalmological Society, vol. 54, no. 8, pp. 1213-1218, 2013. 


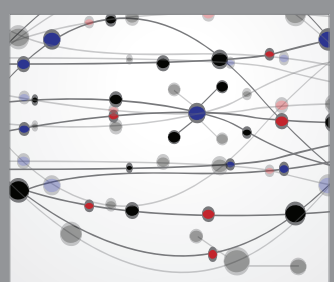

The Scientific World Journal
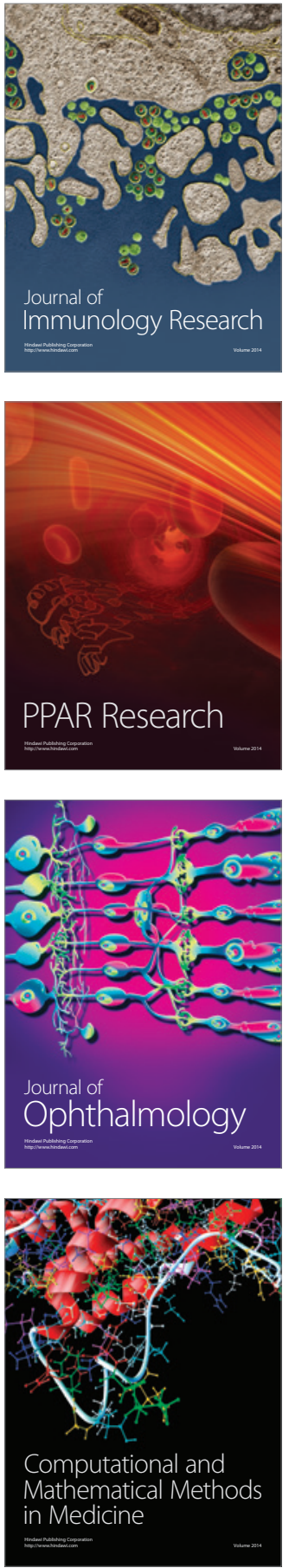

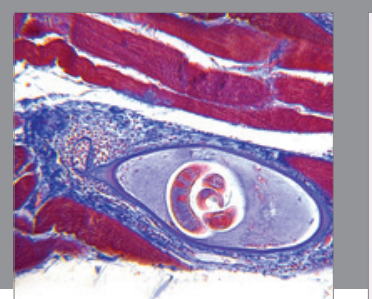

Gastroenterology Research and Practice

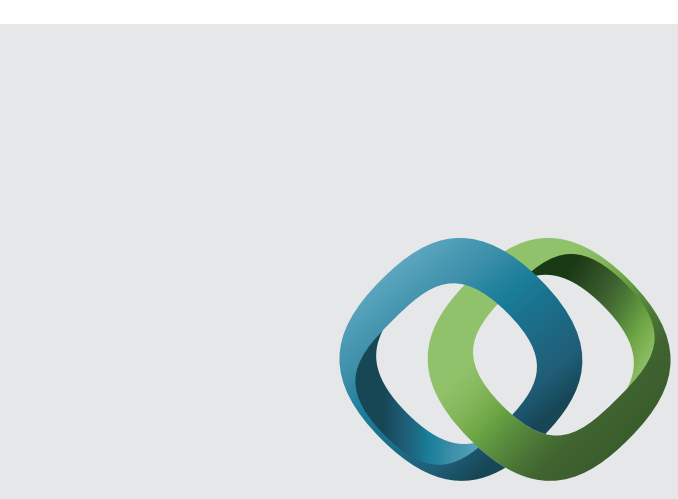

\section{Hindawi}

Submit your manuscripts at

http://www.hindawi.com
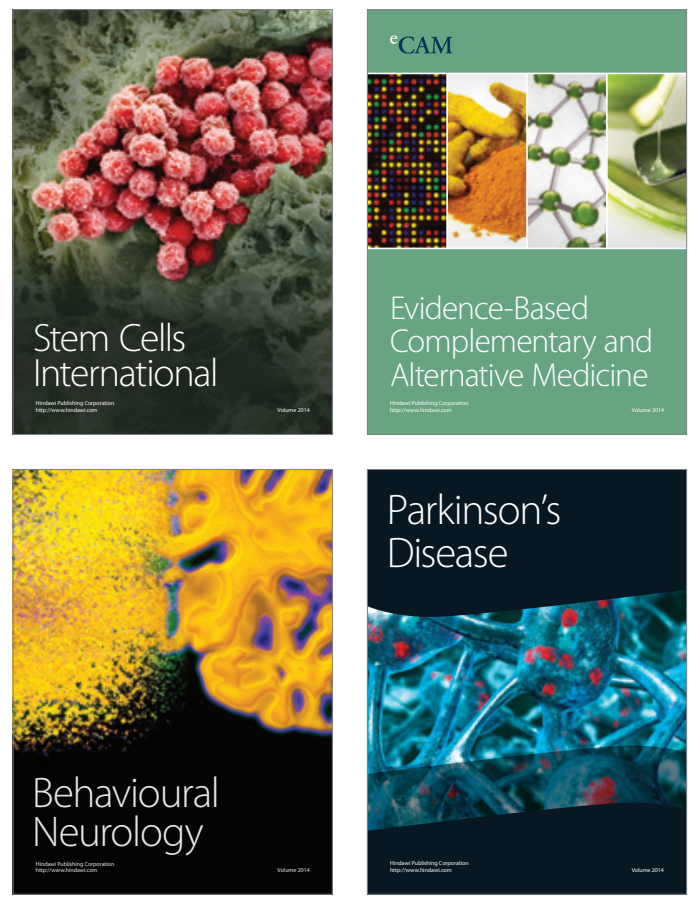
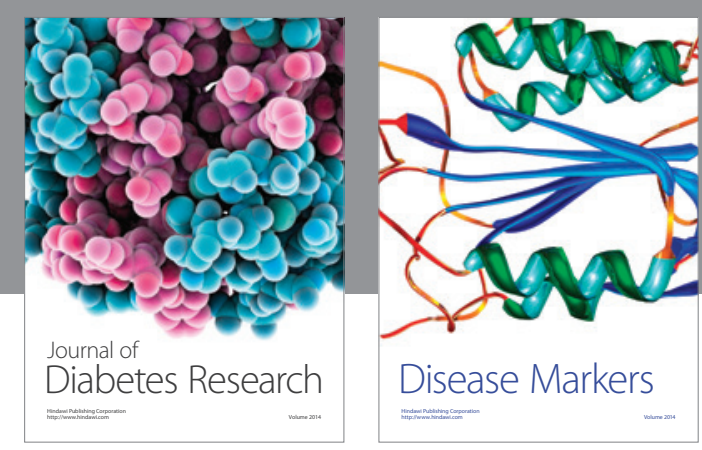

Disease Markers
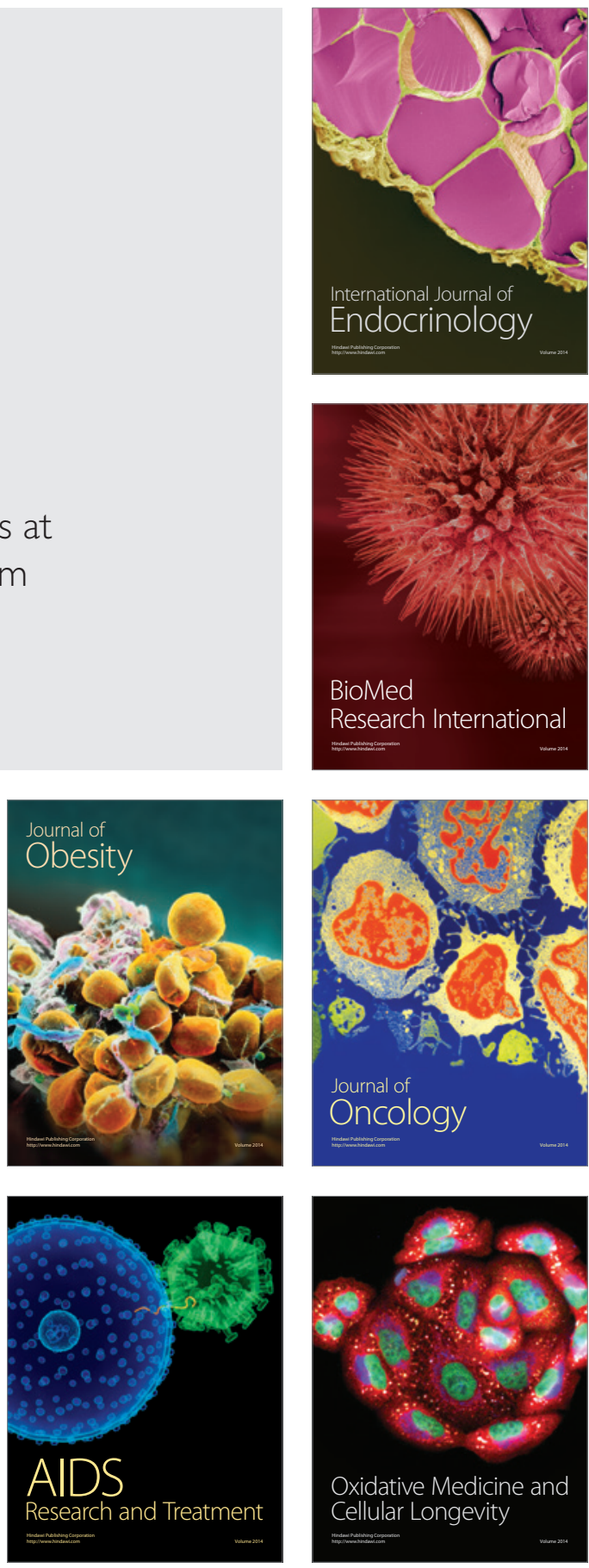